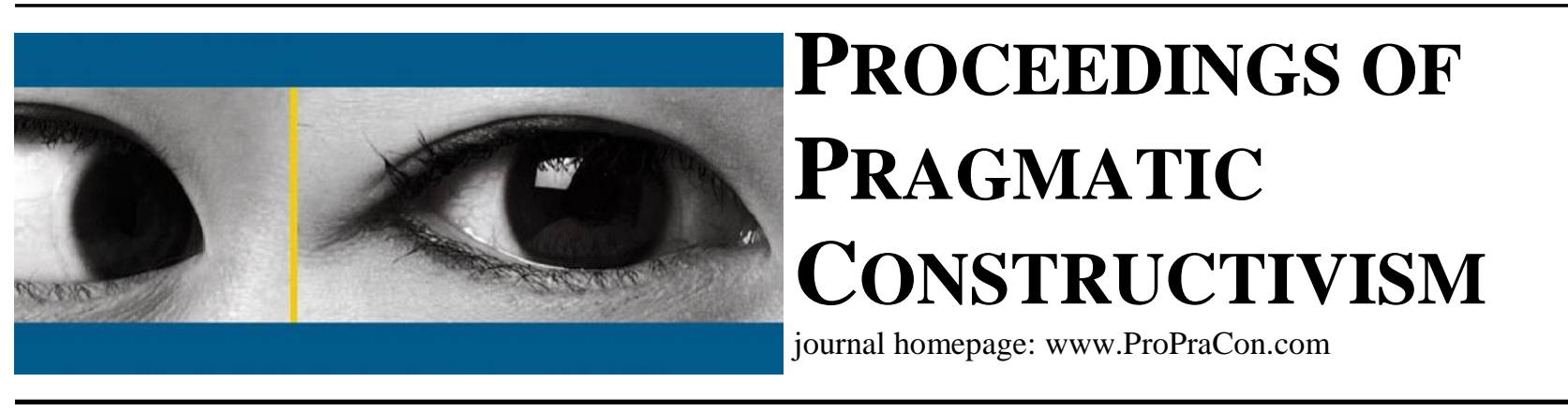

\title{
Editorial: Pragmatic Constructivism for making a difference in organizations
}

\author{
Morten Jakobsen, \\ Department of Management, Aarhus University \\ Email: mja@mgmt.au.dk \\ Tuomas Korhonen \\ Cost Management Center at the Tampere University of Technology \\ Email: tuomas.korhonen@tut.fi \\ Teemu Laine, \\ Cost Management Center at the Tampere University of Technology \\ Email: teemu.j.laine@tut.fi
}

It is a great pleasure for us, Morten Jakobsen, Tuomas Korhonen and Teemu Laine, to begin as the new Editorial team in the Proceedings of Pragmatic Constructivism. We wish to thank Hanne Nørreklit and the Editorial Board for this opportunity and, at the same time, wish to extend our thanks to Rainer Lueg who has served as the Editor of the journal during its previous years 2013-2016.

As the newly appointed Co-Editors-in-Chief, we share the interest in the variety of possibilities embedded to the development and use of Pragmatic Constructivism. Moreover, we have the enthusiasm in conducting research that makes difference in organizations both directly and indirectly. In the following, we will present our editorial policy and possible future topics in the journal. Furthermore, we will present the papers published in this issue of Proceedings of Pragmatic Constructivism.

\section{Editorial policy}

Regarding the future of the Proceedings of Pragmatic Constructivism, more specifically, our editorial policy follows three initial guiding thoughts.

1. It is important that the papers published in the journal either represent advancements in pragmatic constructivism or utilize pragmatic constructivism to advance other areas of research. Naturally, such advancements may mean different kinds of contributions. We are happy to observe that the theoretical foundation and conceptual framework related to pragmatic constructivism has grown into a substantial amount of publications (see, e.g., Nørreklit et al., 2016; Nørreklit, 2017). We, as Co-Editors-in-Chief, find that we can therefore pay an increased attention to the contribution requirements for the papers that are being considered for publication in ProPraCon. In other words, to advance academic research on pragmatic constructivism, only scholarly papers that explicitly employ pragmatic-constructivist thought can be accepted for publication. We, however, note that this focus may still mean an ample scope of different approaches - depending on different research traditions. By employing pragmatic-constructivist thought, we refer to using the framework as a metatheoretical framework for analyzing and developing a research problem: papers that e.g. discuss, criticize and/or develop the framework in a constructive way. More particularly, we will consider employing pragmatic constructivism together with, supplemented by, or in contrast to other theoretical approaches and frameworks interesting from the viewpoint of ProPraCon. 
2. We will pay an increased attention to the role of the review processes to clarify the contribution of submitted articles, according to the idea above. We see ProPraCon also as a potential starting point for scholars who wholeheartedly would like to work with pragmatic constructivism. We hope that the editorial board members and other current and potential reviewers of the journal will support our endeavor to improve papers by offering reviews that are constructive and openminded, but of course, with due respect to the essence of pragmatic constructivism. The Editorial team is always available also for providing constructive comments regarding article ideas and submissions for the journal.

3. Regarding the submission formats for the journal, research notes and full papers will be the type publications we would like to publish. The research notes can sometimes be relatively short, and their review process may remain relatively streamlined. Presentations will no longer be considered for publication in the journal, which resembles our ambition to develop the journal solely into a form that is in line with renowned management journals.

\section{Future topics of the journal}

Overall, the Editorial team is committed to further developing the journal. In practice, by building on The Actor-Reality Construction VII conference, at Tampere University of Technology, 2017, the Editorial team wishes to draw attention to the following themes that deserve an increased attention in the pragmatic constructivism research:

First, methodological developments around and relevant to pragmatic constructivism are important especially with respect to the language games, communication, interaction and interventions.

Second, better understanding about ethics, values and accountability (both separately and in connection to each other) is of an increased importance in the society and organizations nowadays, and such a new understanding is desired to find ways to establish better functioning practices.

Third, it is important to unveil and address the possibilities stemming from digitalization and new ways of using numbers in decision-making. We also welcome critical perspectives related to those possibilities. Such criticism might also be required for an increased understanding about each of the matters.

The editorial team is happy that there are ongoing research activities within the network regarding the aforementioned topics. Proceedings of Pragmatic Constructivism serves as one natural outlet for the publications resulting from those research activities. Such publications may be included in the normal issues of ProPraCon or, perhaps also, in special issues dedicated to one of those areas.

In addition to the identified areas of future research mentioned, there are also other possibilities for increasing the attention to the journal with special issues. Proposals regarding such topical areas are continuously welcome. Besides, it would also be possible to challenge the traditional format of the special issues in accounting journal. For instance, a special issue for PhD-students (based on the forthcoming conferences of Actor Reality Construction) is one possibility. Other possibilities include a special issue for a specific discipline and a special issue where we work with alternative forms of literature reviews. All in all, we see plenty of possibilities in terms of scope and content with regard to the future development of the journal.

\section{Current issue}

The current issue of the journal, we believe, is a step towards the intended direction. In the first paper, Lars Bo Henriksen (2017) addresses a central topic in pragmatic constructivism, yet one that has not been adequately scrutinized in prior research. In "Towards Integrating Realities - Pragmatic Constructivism and Arendt's Theory of Action" Henriksen uses Hannah Arendt's writings to understand integration and so contributes to pragmatic-constructivist thought.

In the second paper, Antonio Leotta, Daniela Ruggeri and Monica Castro (2017) discuss the theoretical conditions for validity in performance measures used in hospital planning. Their discussions show how pragmatic constructivism is able to offer guidelines for analysing the validity in performance measures used in hospital planning. They point at the importance of examining the validity of knowledge of past results by verifying the correspondence of performance measures with the past activity of the hospital. Also the co-presence of two main logics which characterised any hospital setting, is interpreted as multiple topoi that guide the organisational actors in recognising the validity of knowledge of past results, verifying the correspondence of performance measures with the past activity of the hospital. 


\section{Concluding remarks}

The papers in the present issue address only some of the vast opportunities related to the enactment of the pragmatic constructivism in research. For instance, in the area of digitalization there is much literature outside the conventional outlets that pragmatic constructivism could contribute to, e.g. in general management literature (e.g., George et al., 2014; George et al., 2016). Naturally, digitalization is not the only theme relevant to researchers outside management accounting with potential for pragmatic constructivism. However, it offers interesting future possibilities for researchers to address the change in 'actorship' once digitalization adds to or removes something from human management. Methodology and issues of ethics also are also universal research topics and can be addressed in a number of organizational and management journals as well as in the area of accounting, and particularly in ProPraCon. However, these topics are only exemplary and do not comprise an exhaustive list of future publication possibilities in ProPraCon. In all, pragmatic constructivist research benefits from the approaches ranging from those that are purely theoretical to those that are deeply engaged with organizational practices.

We hope that the present issue of ProPraCon represents an interesting read for you. Again, we welcome interesting submissions on pragmatic constructivism to the journal and plenty of interesting discussions around this increasingly relevant and impactful research area.

\section{The New Editorial Team}

Associate Professor Morten Jakobsen represents the team in Aarhus University with a specific attention on applying pragmatic constructivism as analytical framework in order to address accounting problems (e.g., Jakobsen et al., 2011; Jakobsen, 2017). His expertise is particularly in management accounting and how accountants can contribute in the process of developing possibilities for a company. Associate Professor, Dr. Teemu Laine and Dr. Tuomas Korhonen work for Cost Management Center, Tampere University of Technology. They have conducted research on pragmatic constructivism in connection with interventionist research approach (Korhonen, 2014; Rantamaa et al., 2014; Korhonen et al., 2016; Laine et al., 2016; Laine et al., 2017). Their expertise is in close industry collaboration combined with a variety of phenomena: e.g., monetization, servitization, digitalization and globalization.

\section{References}

George, G., Haas, M.R., Pentland, A., 2014. Big data and management. Academy of Management Journal 57, $321-326$. George, G., Osinga, E.C., Lavie, D., Scott, B.A., 2016. Big data and data science methods for management research. Academy of Management Journal 59, 1493-1507.

Henriksen, L.B. 2017. Towards Integrating Realities - Pragmatic Constructivism and Arendt's Theory of Action. Proceedings of Pragmatic Constructivism (this issue).

Jakobsen, M., 2017. Comparison of Pragmatic Constructivism and Actor Network Theory, in Nørreklit, H. (Ed.), A Philosophy of Management Accounting: A Pragmatic Constructivist Approach. Routledge, pp. 245-259.

Jakobsen, M., Johanson, I., Nørreklit, H., 2011. An Actor's Approach to Management Conceptual Framework and Company Practices. Djøf/Jurist-og Økonomforbundet.

Korhonen, T., 2014. Performance Measurement Dynamism in Product Development. Tampere University of Technology. Publication; 1218.

Korhonen, T., Stormi, K., Laine, T., Liew, A., 2016. Examining technical and behavioural possibilities in developing fleet services in the machinery manufacturing context. Proceedings of Pragmatic Constructivism 6, 3-13.

Laine, T., Korhonen, T., Suomala, P., Rantamaa, A., 2016. Boundary subjects and boundary objects in accounting fact construction and communication. Qualitative Research in Accounting \& Management 13, 303-329.

Laine, T., Korhonen, T., Suomala, P., Tervala, E., 2017. New Product Development Project Managers as Actors: The Viewpoint of Management Accounting and Control, in Nørreklit, H. (Ed.), A Philosophy of Management Accounting: A Pragmatic Constructivist Approach. Routledge, pp. 117-133.

Leotta, A., Ruggeri, D.; Castro, M. 2017. The validity in performance measures used in hospital planning. Proceedings of Pragmatic Constructivism (this issue).

Nørreklit, H., 2017. A Philosophy of Management Accounting: A Pragmatic Constructivist Approach. Routledge.

Nørreklit, H., Mitchell, F., Raffnsøe-Møller, M., 2016. A pragmatic constructivist approach to accounting practice and research. Qualitative Research in Accounting \& Management 13.

Rantamaa, A., Laine, T., Korhonen, T., 2014. Accounting prototypes supporting product development: integrating different actors' viewpoints. Proceedings of Pragmatic Constructivism 4, 3-13. 